ARTIGOS ORIGINAIS 



\title{
BIOMARCADORES PREDITIVOS EM TECIDOS BUCAIS E SUAS IMPLICAÇÕES NA SAÚDE EM UMA POPULAÇÃO MISCIGENADA DA AMAZÔNIA
}

\author{
Cristina Maria Duarte Valente (D) \\ Universidade Federal do Pará, Belém/PA, Brasi \\ Milene Raiol de Moraes \\ (1D $\triangle$ \\ Universidade Federal do Pará, Belém/PA, Brasil \\ Antonio André Conde Modesto \\ (1) $\bowtie$ \\ Universidade Federal do Pará, Belém/PA, Brasil \\ Leandro Magalhães \\ (1D)
}

Universidade Federal do Pará, Belém/PA, Brasil

Ândrea Kely Campos Ribeiro-dos-Santos

(1D $\bowtie$ 
Os casos de câncer aumentaram mundialmente. Estimam-se, para o Brasil, 14.700 novos casos de Carcinoma de Células Escamosas Oral (CCEO) para o biênio 2018-2019. A maioria dos casos de câncer pode ser prevenida com medidas simples, como estilo de vida saudável, alimentação balanceada e mais natural, higienização, exercícios físicos, somada a exames laboratoriais de triagem que podem ajudar a prevenir ou identificar processos carcinogênicos, como as análises de microRNAs (biomarcadores envolvidos na oncogênese). Considerando o exposto, o objetivo deste estudo foi relacionar fatores socioeconômicos e epigenéticos - nível de expressão do microRNA da família Let-7 ( $m i R$-let-7c), em uma amostra de indivíduos residentes no município de Belém, Pará, Brasil. O resultado da investigação, apesar de se constituir de uma amostra heterogênea, não apresentou diferenças estatísticas na expressão do microRNA let-7c. Esse resultado sugere que no processo da formação da população de Belém, esse biomarcador não sofreu influência da ancestralidade genômica, fazendo dele um bom marcador de risco e que pode ser utilizado como ferramenta em estudos comparativos relacionados ao desenvolvimento do câncer ou doenças infectocontagiosas. Um vasto campo e uma infinidade de biomarcadores ainda podem ser identificados e analisados, resultando em tratamentos menos invasivos, com melhores prognósticos.

Palavras-chave: Fatores socioeconômicos e ambientais; microRNAs; câncer bucal; oncogenes; genética.

\section{PREDICTIVE BIOMARKERS IN ORAL TISSUES AND THEIR HEALTH IMPLICATIONS IN A MYSTICULTURAL POPULATION OF THE AMAZON}

\section{ABSTRACT}

Cancer cases have increased worldwide. In Brazil, there were an estimated 14,700 new cases of oral squamous cell carcinoma (CCEO) in the 2018-2019 period. Most cases of cancer can be prevented with simple measures such as a healthy lifestyle, balanced diet, hygiene, exercise, and screening tests, that can help prevent or identify cancerous processes such as microRNA analyses (biomarkers involved in oncogenesis). The aim of this study was to relate socioeconomic and epigenetic factors (expression levels of Let-7 family microRNA, miR-let-7c) in a sample of individuals living in the city of Belém, Pará, Brazil. Despite the heterogeneous nature of our samples, results did not show statistically significant differences in the expression of let-7c microRNA, showing that this biomarker is not influenced by genomic ancestry in the population of Belém, making it a good risk marker that can be used as a tool in comparative studies related to cancer or infectious diseases. Numerous biomarkers remain unknown and may be identified and analyzed, resulting in less invasive treatments and better prognoses.

Keywords: Socioeconomic factors; microRNAs; oral cancer; oncogenes; genetics

\section{BIOMARCADORES PREDICTIVOS EN TEJIDOS ORALES Y SUS IMPLICACIONES PARA LA SALUD EN UNA POBLACIÓN MÍSTICA DE LA AMAZONÍA}

\section{RESUMEN}

Los casos de cancer han aumentado en todo el mundo. Se estima, para Brasil, 14.700 nuevos casos de carcinoma de células escamosas orales (CCEO) para el bienio 2018-2019. El cancer se puede prevenir con un estilo de vida saludable y con análisis de microARN, biomarcadores implicados en la oncogénesis. El objetivo de este estudio fue evaluar la asociación entre el nivel de expresión de los microARN de la familia Let-7 (miR-let-7c) - factores epigenéticos y socioeconómicos de individuos que viven en la ciudad de Belém (Pará), Brasil. La muestra, a pesar de la heterogeneidad, no presentó diferencias estadísticas en la expresión del microARN let-7c que muestra que, en el proceso de formación de la población de Belén, este biomarcador no sufre influencia de ascendencia genómica, por lo que es un buen marcador de riesgo que puede utilizarse como herramienta en estudios comparativos relacionados con el cancer o las enfermedades infecciosas. Todavía se puede identificar y analizar un vasto campo y una multitud de biomarcadores, lo que resulta en tratamientos menos invasivos, con un mejor pronóstico.

Palabras clave: Factores socioeconómicos y ambientales; microARN; cáncer oral; oncogenes; genética. 


\section{INTRODUÇÃO}

O câncer representa um importante problema de saúde pública mundial devido ao seu impacto social e aos elevados índices de morbimortalidade. No Brasil, as unidades de alta complexidade do Sistema Único de Saúde são responsáveis pela maioria dos atendimentos (Cervigne et al. 2009). Entre os anos de 2003-2007, observou-se um aumento no número de casos em todas as regiões brasileiras, resultado de diferentes variáveis entre as quais: (a) envelhecimento populacional, genética, exposição a agentes infecciosos como Helicobacter pylori, o vírus do papiloma humano (HPV), as hepatites B e C e o vírus Epstein-Barr (Nasman et al. 2019); (b) a poluição do ar, da água e do solo com substâncias químicas carcinogênicas também contribui para o ônus do câncer em diferentes graus, dependendo das configurações geográficas; e (c) o consumo de tabaco, que na sua composição tem mais de 7.000 produtos químicos, dos quais mais de 50 estão relacionados ao desenvolvimento do câncer. Dentre essas variáveis destacamos o câncer de pulmão, de esôfago, de laringe (boca), de boca, de garganta, de rim, de bexiga, do pâncreas, do estômago e do colo do útero. Portanto, o tabaco constitui-se no maior fator de risco evitável para a mortalidade por câncer, já que 6 milhões de pessoas tabagistas a cada ano apresentam sintomas da doença (Blot et al. 1988, Prado 2014).
Atividades de prevenção primária ao câncer devem ser incorporadas ao nosso cotidiano, principalmente por aqueles indivíduos com variantes moleculares (presentes na molécula de DNA ou RNA) que necessitam de um maior controle sobre os fatores ambientais, além da prática de atividades físicas regulares, visando a diminuição à susceptibilidade do desenvolvimento do câncer e seus fatores de risco associados (Guerra, Moura Gallo \& Mendonça 2005, Nogueira 2010, Ribeiro-dos-Santos et al. 2010, Castro 2009).

Do ponto de vista biológico, o câncer é resultado da acumulação gradual de mutações genéticas e epigenéticas que afetam principalmente genes drivers, alterando a homeostase das funções essenciais das células (Tomasetti et al. 2017). Em resposta a essas alterações drivers, a célula adquire uma série de novas habilidades, incluindo a capacidade de emitir sinais de proliferação contínua, bloquear os sinais de supressão tumoral, resistir à morte celular, ajustar o metabolismo energético, escapar da resposta imune, induzir angiogênese, habilitar imortalidade replicativa celular e ativar o mecanismo de invasão e metástase em órgãos distantes (Hanahan \& Weinberg 2011, Bourguignon 2012, Yang et al. 2014). A maioria dos cânceres pode se apresentar com frequência variável em função das características biológicas e culturais de cada região do país (Guerra et al. 
2005, Yanaihara et al. 2006, Shiiba et al. 2013, Yang et al. 2014).

Diante desta realidade, torna-se necessário o estudo dos mecanismos que envolvam a carcinogênese, tanto do ponto de vista estrutural como do ponto de vista funcional, a fim de se entender mais sobre essa doença e assim propor novas abordagens preventivas, diagnósticas e terapêuticas, uma vez que a interação entre o conjunto de mecanismos (Figura 1) faz com que o câncer seja muito complexo, de difícil manejo e um grande impacto para a saúde pública mundial (Castro 2009).

Em relação ao câncer da cavidade oral (CCEO), para o Brasil, estimam-se 14.700 novos casos de carcinoma de CCEO, distribuídos entre 11.200 novos casos de câncer da cavidade oral entre homens e 3.500 entre mulheres para cada ano do

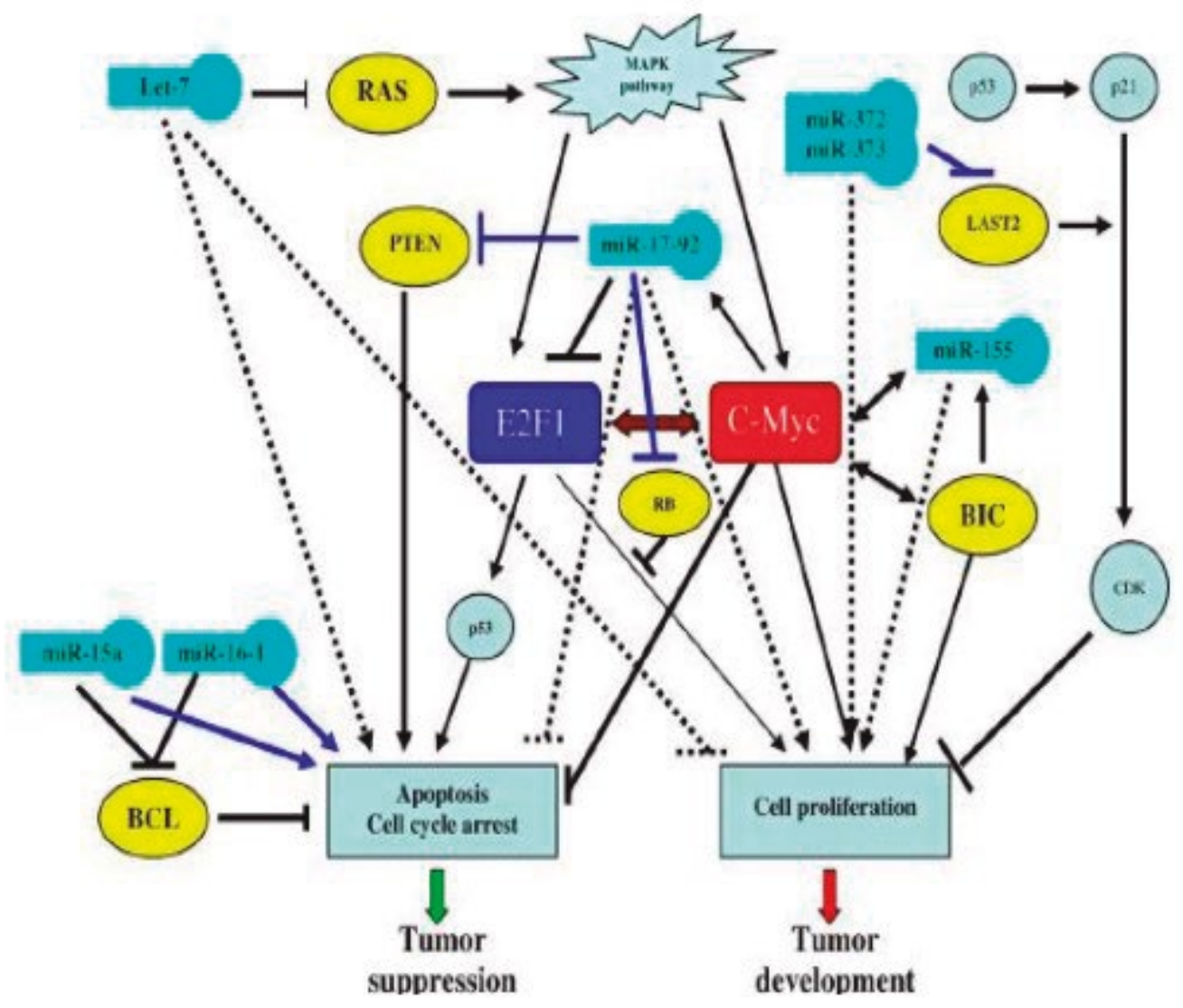

Figura 1 - Modelos dos mecanismos moleculares dos miRNAs envolvidos na patogênese do câncer. Neste modelo ressaltamos o let-7, que funciona como supressor tumoral (Zhang et al. 2015). 
biênio 2018-2019, números que correspondem a um risco estimado de 10,86 novos casos a cada 100 mil homens, ocupando a quinta ( $5^{\text {a }}$ ) posição; e de 3,28 para cada 100 mil mulheres, sendo o $12^{\circ}$ mais frequente entre todos os cânceres. Segundo dados do Inca (2018), sem considerar os tumores de pele não melanoma, o câncer da cavidade oral em homens é o $6^{\circ}$ mais frequente na Região Norte (3,59/100 mil). Para as mulheres, é o $12^{\circ}$ mais frequente na região (1,78/100 mil). No estado do Pará, a estimativa foi de 220 casos novos, sendo 140 nos homens e 80 nas mulheres. E, no município de Belém, 60 novos casos, sendo 30 nos homens e 30 nas mulheres de câncer da cavidade oral.

Em 2018, foram estimados 246 mil casos novos de cânceres de língua e cavidade oral em homens e 108 mil em mulheres, no mundo, sendo mais comum em homens acima dos 40 anos do que em mulheres. O risco estimado para essa neoplasia foi de 6,4/100 mil em homens e 2,9/100 mil em mulheres (Bray et al. 2018, Ferlay et al. 2018). Lábios, gengivas, bochechas, céu da boca, língua e a região embaixo da língua são estruturas anatômicas afetadas pelo câncer de boca (Silva 2019).

Por causa da maioria dos cânceres se desenvolver em pessoas com idade avançada, presume-se que o envelhecimento populacional (tempo de vida prolongado) seja um dos principais fatores envolvidos na carcinogênese, pois ocorre alteração do equilíbrio entre o mecanismo da apoptose e proliferação celular afetado pelo surgimento de mutações germinativas ou somáticas (Dantas et al. 2009, Prado 2014) no genoma nuclear e/ ou mitocondrial. Tais mutações podem ocorrer devido a exposição a determinadas substâncias mutagênicas ou "carcinógenos" (Andreghetto et al. 2011, Cavalcante et al. 2019).

Atualmente, os testes genéticos identificam a presença principalmente de oncogenes e supressores tumorais específicos para certos tipos de cânceres, marcadores tumorais que revelam a presença de substâncias produzidas pelas células cancerosas, indicando o grau do tumor, contribuindo para a precocidade do diagnóstico (Prado 2014).

Considerando que o câncer oral é uma doença agressiva, mutiladora que frequentemente deixa sequelas irreversíveis na fala, respiração, deglutição e pode evoluir para o óbito (Argyris et al. 2008, Ferlay et al. 2010, Jemal et al. 2009, Nasman et al. 2009), comprometendo a saúde e a qualidade de vida, faz-se necessária a investigação de biomarcadores preditivos que possam auxiliar no diagnóstico precoce, obtendo-se melhor prognóstico e tratamentos menos invasivos e agressivos.

O microRNA let-7C é um biomarcador natural do nosso organismo, regulador do gene $V D R$, hormônio da vitamina D. Quando esse 
microRNA apresenta um perfil de expressão elevado, denominado de hiperexpresso, terá o papel de antibactericida natural eliminando os microrganismos existentes no meio celular, favorecendo a saúde do indivíduo. Por outro lado, quando o let-7c se apresenta com nível de expressão baixa, hipoexpresso, os microrganismos permanecerão no interior das células deixando o organismo vulnerável a qualquer tipo de infecção, como a tuberculose, a hanseníase, incluindo o desenvolvimento do câncer. Portanto, investigações no perfil de expressão deste miRNA podem fornecer uma ferramenta genética importante para o estabelecimento de biomarcadores relacionados a várias doenças como o câncer (Silveira et al. 2012, Harding \& Sherr 2014, Yang et al. 2014).

\section{FATORES DE RISCO PARA 0 CÂNCER}

\section{Fatores Ambientais}

Os fatores de risco mais conhecidos incluem o tabagismo e o consumo excessivo de álcool, sendo que o risco é 30 vezes maior para os indivíduos que fumam e bebem do que para aquelas pessoas que não o fazem (Silva 2019). Dentre outros fatores de risco, encontra-se a exposição ao sol sem proteção. Mais de 30\% dos pacientes com câncer nos lábios trabalham expostos aos raios solares (Inca 2014), o excesso de gordura corporal, a infecção pelo HPV relacionada ao câncer de orofaringe e fatores relacionados à exposição ocupacional (Silva 2019).

Nas pessoas que fazem uso de tabaco nas mais diferentes formas, aumenta-se em $90 \%$ o risco de câncer de boca, garganta ou laringe (Hukkanen et al. 2005). As bebidas alcoólicas também aumentam esse risco em torno de $75 \%$ a $80 \%$. A combinação do uso de cigarro e bebida é a mais fatal (Blot et al. 1988). Alguns estudos mostram a influência do trauma crônico na mucosa oral de pacientes com lesões potencialmente malignas e em pacientes com câncer, por isso, acredita-se que o uso de dentaduras, pontes ou coroas mal-adaptadas também sejam um fator de risco para o câncer oral (Piemonte, Lazos \& Brunotto 2010).

Agentes infecciosos também têm papel importante no aparecimento do câncer, por exemplo, cita-se tipos de HPV (Human Papiloma Vírus) associados ao desenvolvimento do câncer de colo de útero, também encontrados em $20 \%$ a 30\% dos cânceres de amígdalas, o que sugere um fator para o desenvolvimento de câncer de garganta em $20 \%$ das pessoas (Lima et al. 2014).

Conservantes de carnes e embutidos, salmouras, raios ultravioletas, radiações ionizantes, bebidas alcólicas, herbicidas, pesticidas e fungicidas utilizados indiscriminadamente em produtos destinados ao consumo humano, também podem resultar no surgimento de tumores malignos (Andreghetto et al. 2011, Linhares 2014). 


\section{Fatores Epigenéticos}

Os microRNAs (ou miRNAs) são pequenas moléculas de RNA não codificantes compostas por cadeias de 18 a 25 nucleotídeos, de fita dupla e pertencem a uma longa família altamente conservada (Ambros 2004, O'Donnell et al. 2005, El-Hani et al. 2006, Ivey \& Srivastava 2010). Elas controlam diversas vias de regulação, como o desenvolvimento, diferenciação celular, proliferação, envelhecimento do organismo, senescência e apoptose. Portanto, a desregulação da expressão de miRNAs contribui para a manifestação de algumas doenças, dentre elas, o câncer (Yanaihara et al. 2006, Calin et al. 2007, Farazi et al. 2011). O processo de seleção é dirigido pela interação molecular entre a extremidade 5'UTR do regulador e a extremidade 3'UTR do regulado e pelo reconhecimento da sequência seed (2-8 nucleotídeos iniciais da extremidade 5’UTR do miRNA) (Figura 2 e 3).

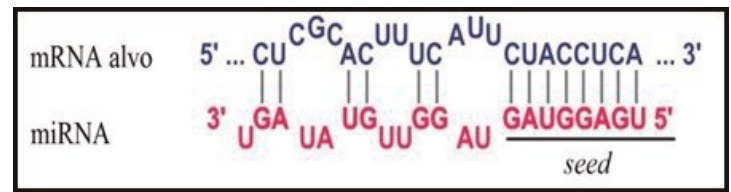

Figura 2 - Sequência de microRNAs com destaque em Seed. Fonte: Ribeiro-dos-Santos et al. (2010)
Geralmente, um miRNA regula centenas de genes-alvo, alternativamente, um gene pode ser reprimido por centenas de miRNAs, resultando na formação de vias de regulação complexas (Bartel et al. 2008). A justificativa do uso desses elementos é que, em média, $60 \%$ dos mRNAs apresentam uma ou mais sequências evolutivamente conservadas que estão previstas para interagir com miRNAs (Krek et al. 2005, Lewis et al. 2005, Bartel et al. 2008, Friedman et al. 2009). Outro fundamento é o auxílio das análises de bioinformática, que podem prever que a região 3' UTR de um único gene como alvo frequente de vários miRNAs diferentes (Krek et al. 2005, Lewis et al. 2005), muitas dessas análises mostram a importância do controle da regulação gênica em genes fundamentais para o desenvolvimento e manutenção da vida foram, e têm sido validadas experimentalmente, demonstrando a cooperação do miRNA para regulação da expressão (Ivanovska \& Cleary 2008).

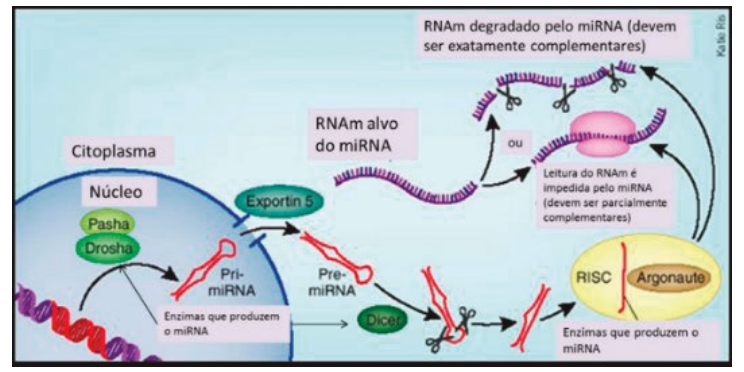

Figura 3 - Biogênese ou geração de miRNAs e os mecanismos de inibição da síntese proteica. Um miRNA primário (pri-miRNA) é transcrito ou produzido no núcleo. Fonte: www.institutonanocell.org.br1300 × 642 . 
As evidências biológicas têm demonstrado que o surgimento do câncer envolve alterações em oncogenes, genes supressores de tumor, genes controladores do reparo de DNA, do ciclo celular e adesão celular, assim como envolve também inúmeras alterações epigenéticas, em que se destacam os microRNAs. Esses elementos têm emergido como principais agentes da estabilidade e do equilíbrio celular (também denominada de homeostase), portanto, a análise da expressão dos miRNAs e a desregulação de sua função pode fornecer informações valiosas das diversas doenças humanas (Ross \& Davis 2011, Glaser et al. 2009).

\section{MICRORNAS NO CÂNCER ORAL}

Os miRNAs regulam genes alvos e desempenham um papel crucial na iniciação e progressão do câncer oral e alterações nessa expressão determinam uma assinatura específica que pode auxiliar no diagnóstico, prognóstico e alvos terapêuticos nos casos de carcinoma de CCEO (Lo et al. 2012, Shao et al. 2013, Min et al. 2015). Estudos mostraram a expressão desregulada de miRNAs no tecido tumoral ou em linhagens celulares derivadas de câncer oral, quando comparadas a amostras de tecidos adjacentes ao tumor indicando seu potencial papel no desenvolvimento da doença (Figura 4) (Andreghetto et al. 2011, Nagadia et al. 2013).

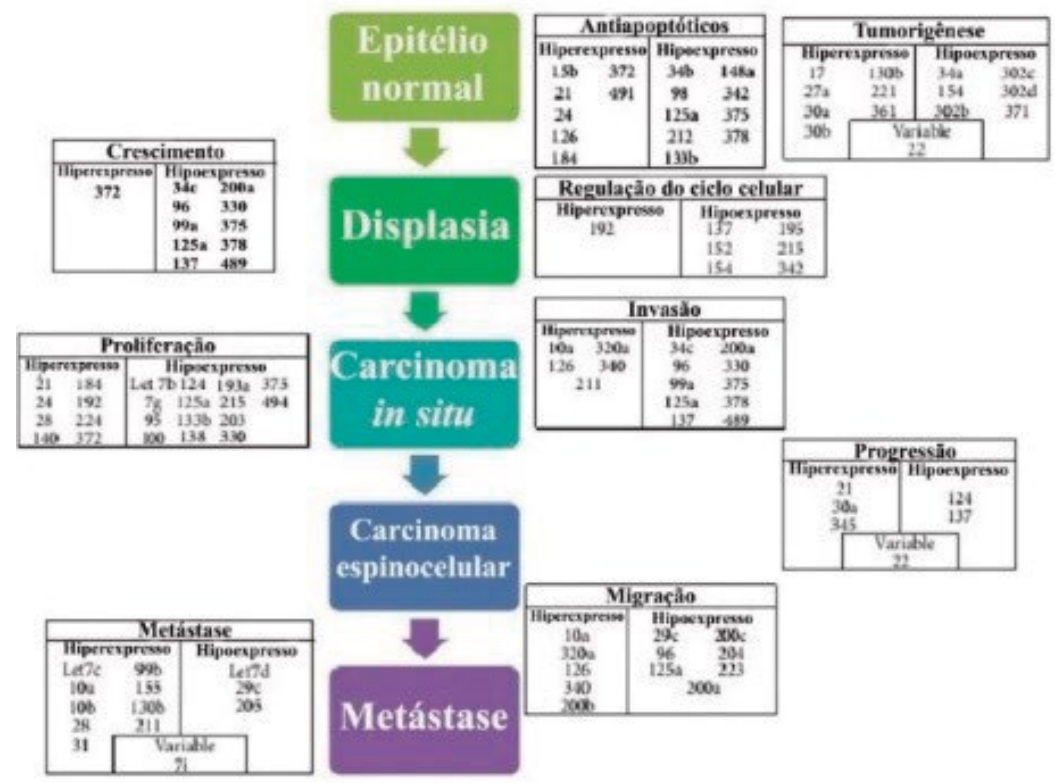

Figura 4 - MiRNAs desregulados em cada etapa do processo de desenvolvimento ao CCE. Fonte: Adaptado de Nagadia et al. (2013). 
Vários autores apontaram vários tipos de microRNAs relacionados com o desenvolvimento de diversas patologias da cavidade oral, como o CCEO, conforme tabela 1.

Adicionalmente, estudos recentes têm sugerido que marcadores genéticos ligados ao grupo étnico específico a que os indivíduos pertencem pode influenciar na sobrevida de pacientes com câncer orofaríngeo. No estudo de Megwalu e Ma (2017), os indivíduos de ascendência africana obtiveram piores índices, atribuídos, provavelmente, às piores condições socioeconômicas dificultando o acesso ao tratamento nesses indivíduos. Silva et al. (2017) relataram em seus estudos o efeito da ancestralidade genética no risco de suscetibilidade ao desenvolvimento do câncer gástrico, em uma população da Amazônia brasileira, sendo que a composição étnica do grupo caso investigado foi constituída de $41 \%$ europeia, $26 \%$ africana e $33 \%$ nativa americana, em comparação as contribuições ancestrais do grupo de controle que foram $47 \%$ europeias, $23 \%$ africanas e $30 \%$ nativa americana.

Tabela 1 - miRNAs avaliados em estudos de investigação oncológica e em publicações no câncer oral.

\begin{tabular}{|c|c|c|}
\hline mirRNA & Doenças e Tecidos & Referências \\
\hline hsa-miR-21 & $\begin{array}{l}\text { Diversos tipos de cânceres } \\
\text { Câncer oral (leucoplasias) }\end{array}$ & $\begin{array}{l}\text { (Huang 2009b, Huang 2009, Avissar et } \\
\text { al. 2009, Reis et al. 2010, Ren et al. 2010, } \\
\text { Kawakita et al. 2014, Brito et al. 2013). }\end{array}$ \\
\hline$h s a-m i R-181 b$ & Hiperexpresso em displasias orais & (Cervigne et al. 2009, Santhi et al 2013). \\
\hline hsa-miR-345 & Hiperexpresso em displasias orais & (Cervigne et al. 2009, Santhi et al 2013). \\
\hline hsa-miR-96 & Hiperexpresso em displasias orais & (Cervigne et al. 2009, Santhi et al 2013). \\
\hline hsa-miR-31 & $\begin{array}{l}\text { Hiperexpresso no câncer oral em todos os estágios } \\
\text { Hiperexpressão na saliva } \\
\text { Hiperexpressão na leucoplasias e câncer oral }\end{array}$ & (Harris et al. 2012, Hung et al. 2014). \\
\hline hsa-miR-221 & $\begin{array}{l}\text { Distingue tecido livre de câncer de outro com câncer } \\
\text { Hiperexpressão em linhagens celulares e câncer oral. }\end{array}$ & $\begin{array}{l}\text { (Avissar-Whiting et al. 2010, Shiiba et al. } \\
\text { 2013). }\end{array}$ \\
\hline hsa-miR-375 & Distingue tecido livre de câncer de outro com câncer & (Avissar-Whiting et al. 2010). \\
\hline hsa-miR-18 & Hiperexpressão em linhagens celulares e câncer oral. & $\begin{array}{l}\text { (Avissar-Whiting et al. 2010, Shiiba et al. } \\
\text { 2013). }\end{array}$ \\
\hline$h s a-m i R-451$ & Expressão global em câncer oral fixado em ormol & (Hui et al. 2010). \\
\hline Let-7c & $\begin{array}{l}\text { Processos inflamatórios da cavidade oral } \\
\text { Participação no CCEO }\end{array}$ & $\begin{array}{l}\text { (Lopes 2016, Zhang et al. 2015, Fassina et al. } \\
\text { 2011). }\end{array}$ \\
\hline
\end{tabular}


Adicionalmente, Pereira et al. (2012) em outra publicação também da região Amazônica, relataram sobre a ancestralidade genômica do município de Belém (PA), com uma população que apresentou uma distribuição de 53,7\% de europeus, $16,8 \%$ africanos, e $29,5 \%$ de nativos americanos.

Diante de vários estudos, observa-se a importância de se associar os fatores do ambiente, socioeconômicos, alimentares e de atividade física, com a presença de marcadores biológicos (biomarcadores) que poderão ser capazes de identificar e auxiliar para a prevenção em maior ou menor risco envolvido no processo de adoecimento, quer seja de uma população ou de um indivíduo (Guerra et al. 2005, Nogueira 2010, Ribeiro-dosSantos et al. 2010, Castro 2009). Para isso, propomos detectar a variação da expressão do miRNA-let-7c, de forma precoce, em relação à carcinogênese oral, associando com os fatores socioeconômico e alimentar por causa da contribuição ancestral ímpar presente principalmente nas populações que habitam a região amazônica, como a população miscigenada de Belém.

Portanto, investigações no perfil de expressão do miRNA-let-7c podem fornecer uma ferramenta genética/epigenética importante para o estabelecimento de biomarcadores relacionados a várias doenças, dentre elas o câncer (Silveira et al. 2012, Harding \& Sherr 2014, Yang et al. 2014).

\section{MATERIAL E MÉTODOS}

Trata-se de uma pesquisa de campo descritivo/quantitativo de amostras sem câncer de 100 indivíduos voluntários que residem no município de Belém, estado do Pará. A coleta foi realizada de 5/12/2016 até 10/1/2017 e encontrase dividida em 50 indivíduos do setor privado de saúde (Consultório odontológico particular: SPRS, situado na Av. Senador Lemos, n. 100) e 50 indivíduos do setor público de saúde (Unidade de Saúde da Sacramenta, situada na Av. Senador Lemos, $\mathrm{s} / \mathrm{n})$.

A realização desta pesquisa segue os princípios de Helsinque e da Resolução 466/12, do Conselho Nacional de Saúde/Ministério da Saúde. O estudo foi aprovado pelo Comitê de Ética Institucional do Hospital Universitário João de Barros Barreto (CAAE nº 56822516.1.0000.0018; Parecer: 1.906.415). Todos os participantes deram seus consentimentos informados por escrito e assinado (TCLE). Os indivíduos que aceitaram participar da pesquisa são residentes no município de Belém, estado do Pará, de ambos os sexos, maiores de 18 anos.

A totalidade dos indivíduos foi investigada em relação aos fatores ambientais modificáveis, como os hábitos tabagistas, etílicos, ambos e sem hábitos deletérios, assim como em relação à expressão de um marcador epigenético - o microRNA let-7c.

Os fatores ambientais, aqui incluídos como 
dados socioeconômicos, foram apresentados ao paciente e em seguida realizados pela aplicação de um formulário individual e sucinto, antes do atendimento. Nele existiam perguntas e respostas diretas que dizem respeito à existência ou não de hábitos tabagistas, etílicos, ambos e sem hábitos deletérios.

No que diz respeito aos fatores epigenéticos, eles foram provenientes de amostras obtidas por raspado da mucosa oral com escova apropriada, acondicionadas em tubos Eppendorf com $500 \mu \mathrm{L}$ de água DEPC $+500 \mu \mathrm{L}$ de RNA later (Ambion) $+200 \mu \mathrm{L}$ de Ampicilina 2g, armazenadas a $-80^{\circ} \mathrm{C}$. Os RNAs foram extraídos com TRIzol ${ }^{\circledR}$ Reagent (Life Technologies, CA, USA), seguindo o protocolo do fabricante, hidratados com água DEPC e armazenadas à temperatura de $-80^{\circ} \mathrm{C}$. As concentrações de RNA foram determinadas com o kit específico para RNA - Qubit® RNAAssay Kit (Life Technologies, CA, USA), medido no equipamento Qubit® 2.0 Fluorometer (Life Technologies, CA, USA). Obtivemos o DNA por meio da reação de Transcriptase Reversa, utilizando o kit TaqMan ${ }^{\circledR}$ Micro-RNA RT (Life Technologies, Foster City, CA, EUA) segundo as instruções do fabricante e o estocamos a $-20^{\circ} \mathrm{C}$ para posterior uso. Utilizamos o programa sugerido pelo fabricante do kit. Nessa etapa, os primers são específicos para a molécula de miRNA, além da síntese do controle endógeno (RNU24), que corrige e normaliza os resultados. A etapa seguinte foi a Reação em Cadeia da Polimerase Quantitativa (qPCR) em Tempo Real- (PCR em tempo real) para a análise da expressão utilizando o equipamento 7.500 Real Time PCR System (Applied Biosystems, EUA). Todas as reações foram feitas em triplicata, foi transcrito um pequeno RNA sintético (RNU24) que foi utilizado como endógeno, a fim de favorecer uma quantificação relativa e um NTC, para avaliar possíveis contaminações. A análise dos resultados foi realizada por quantificação relativa, mediante o método Threshold Cycle (CT) comparativo.

A fim de evitar associação espúria entre os polimorfismos genéticos e os grupos de indivíduos do estudo, decorrente de subestruturação genética populacional, foram estimadas a proporção de mistura interétnica das amostras, com um painel de 61 MIA como previamente descrito (Santos et al., 2010, Colares et al. 2014, Cardena et al. 2014, Ota et al. 2013).

A metodologia do $\Delta \mathrm{Ct}$ foi utilizada para análise dos dados. Em seguida, calculou-se $2^{-\Delta C T}$ e o respectivo fold change entre as amostras. As diferenças entre as amostras foram calculadas por meio do teste U - Mann Whitney test, em que os valores de $p \leq 0,01$ foram considerados significativos (escolhemos neste teste o valor de $p \leq 0,01$, porque o número amostral era pequeno e as amostras eram 
de tamanhos diferentes). As frequências alélicas nas amostras de caso e controle foram estimadas por contagem gênica, e os desvios do equilíbrio de Hardy-Weinberg foram realizadas pelo cálculo de qui-quadrado com correção de Bom Ferroni. Os haplótipos e as frequências haplotípicas foram estimadas com o software PHASER 2.0 (Stephens \& Donnelly 2003). Todos os outros testes estatísticos para a análise de associação das características socioeconômicas e biológicas (microRNAs) entre os grupos foram realizadas pelo teste de quiquadrado de Pearson dentro do pacote estatístico SPSS18.0 para Windows ${ }^{\circledR}$. Significância estatística foi definida com p-valor $<0.05$ com 2 desvios padrões. As proporções interétnicas individuais, considerando três populações ancestrais (Europeu, Africano e Nativo Americano) foi estimada com o programa STRUCTURE 2.3.3 com um burn-in de 200,000 e 200,000 correções de Markov Chain Monte Carlo após cada burn-in (Pritchard et al. 2000). A associação estatística entre caso e controle após as correções por estratificação populacional foi feita com o software STRAT (Pritchard et al. 2000).

\section{RESULTADOS E DISCUSSÕES \\ Análise dos dados socioeconômicos}

$\mathrm{Na}$ presente amostra, observou-se um percentual médio de $72 \%$ de mulheres para $28 \%$ de homens que realizam a busca ativa por atendimento de saúde na população da cidade de Belém. Esses resultados corroboram os dados da literatura (Moro et al. 2018). Em nossos resultados, observamos uma diferença estatisticamente significativa do sexo feminino $\left(\mathrm{X}^{2}=19,36 ; p^{<} 0,001\right)$

Quando associamos o uso do cigarro ao sexo, encontramos valores significativos de $\mathrm{p}=0.04$ para o sexo feminino, demonstrando que há uma probabilidade 11 vezes maior de que as mulheres façam uso do cigarro em relação aos homens na presente amostra. Ou seja, a probabilidade de a mulher vir a desenvolver alguma doença associada ao tabagismo com a probabilidade de agravamento torna-se mais alta nessas mulheres do que em relação aos que não são tabagistas. Esses dados assemelham-se aos encontrados na literatura pesquisada (Castro 2009).

Em relação ao tabagismo, 24\% dos usuários do setor privado fazem ou fizeram uso do cigarro, já no setor público esse percentual foi de $42 \%$ (Tabela 2). Encontramos um número bem superior à média citada pela literatura pesquisada, que é de 4,9\% (Vigitel 2018), destacando que a capital paraense é a que possui menor número de fumantes do país (Vigitel 2018). Nossos resultados mostram a maior frequência encontrada, em torno de 3 a 5 cigarros diários (6\%) nos dois grupos analisados; de quatro vezes ou mais por semana (10\%) no setor privado e duas a três vezes por semana no setor 
público. Apenas 4\% dos usuários dos dois grupos admitiram fumar mais de 20 cigarros/dia, ressaltase que a maior incidência foi dos entrevistados que não fazem uso de cigarros, sendo $(82 \%)$ do setor privado e (84\%) do setor público, fator positivo de mudança de comportamento (Tabela 3).

Nos últimos nove anos houve uma queda expressiva do consumo de cigarros; essa redução do consumo foi em torno de $30,7 \%$ resultando em melhoria na qualidade de vida (Prado 2014, Inca 2018, Vigitel 2018), esse resultado reflete a veiculação massiva das campanhas publicitárias nacionais realizadas pelo Ministério da Saúde.

A Pesquisa Nacional de Saúde de 2014 cita que o estado do Pará aparece alinhado a uma tendência nacional, pela qual os homens são os que mais usam produtos do tabaco. De cada 1.000 entrevistados no estado do Pará, 27\% se declararam fumantes, dos quais $18 \%$ eram homens e $8,9 \%$ mulheres (Brasil 2004, Inca 2018).
No estudo de Ferreira et al. (2013) observase uma diferença estatisticamente significativa entre "fumantes e ex-fumantes" e "média diária de cigarros" no que concerne às quantidades utilizadas $\left(\chi^{2}=44.44 ; p<0,001\right)$. Outro estudo (Prado 2014) investigou a dependência do tabaco e a qualidade de vida dos fumantes em relação a ex-fumantes e não fumantes, correlacionando a qualidade de vida com o grau de dependência nicotínica pelo QTF. Os autores avaliaram 45 fumantes, 43 ex-fumantes (12 anos de abstinência) e 64 não fumantes. Quanto ao grau de dependência nicotínica, todos os grupos apresentaram dependência à nicotina em graus diferentes, entretanto, um resultado interessante obtido nesse trabalho foi que os ex-fumantes apresentaram quesitos sugerindo que a interrupção do hábito de fumar pode ter melhorado a qualidade de vida desses indivíduos. Independente dos artigos descritos acima, e da constatação dos prejuízos que o tabagismo traz ao dia a dia desses indivíduos, tal

Tabela 2 - Distribuição percentual dos grupos de indivíduos atendidos no sistema de saúde particular e público, sobre tabagistas, ex-tabagistas e etilistas dos usuários. Elaboração: Questionário aplicado pelos autores da pesquisa.

\begin{tabular}{|l|c|c|c|c|c|c|}
\hline \multicolumn{4}{|c|}{ Setor Privado } & \multicolumn{3}{c|}{ Setor Público } \\
\hline & $\begin{array}{c}\text { Usuários } \\
\text { que fumam }\end{array}$ & $\begin{array}{c}\text { Usuários que } \\
\text { já fumaram }\end{array}$ & Etilistas & $\begin{array}{c}\text { Usuários } \\
\text { que fumam }\end{array}$ & $\begin{array}{c}\text { Usuários que } \\
\text { já fumaram }\end{array}$ & Etilistas \\
\hline Sim & $2(4 \%)$ & Sim $10(20 \%)$ & $18(36 \%)$ & Sim $2(4 \%)$ & Sim $20(40 \%)$ & $8(16 \%)$ \\
\hline Não & $48(96 \%)$ & Não $40(80 \%)$ & $13(26 \%)$ & Não $48(96 \%)$ & Não 30 (60\%) & $25(50 \%)$ \\
\hline & & Socialmente & $19(38 \%)$ & & Socialmente & $17(34 \%)$ \\
\hline
\end{tabular}


fato parece não afetar essa rotina, uma vez que a maioria continua a fazer uso do cigarro (Ferreira et al. 2013).

Em relação ao etilismo, $74 \%$ dos usuários do serviço particular ingerem bebida alcoólica; enquanto no serviço público, esse percentual foi de 50\% (Tabela 2). Uma pesquisa divulgada pelo IBGE em 2013 mostrou que o percentual de homens que consomem bebidas alcoólicas é quase três vezes maior do que o das mulheres no país; $36,3 \%$ (25 milhões) da população masculina fazem uso de algum tipo de bebida alcoólica, uma vez ou mais por semana, enquanto $13 \%$ (10 milhões) da população feminina ingere algum tipo de bebida alcoólica (Blot et al. 1988, Inca 2018).

Encontramos $4 \%$ dos usuários do setor privado que fazem uso diário de bebida alcoólica.
A ingestão semanal fica em $30 \%$ e $18 \%$ para os setores privado e público, respectivamente: $22 \%$ (privado) e 48\% (público) dos entrevistados não são etilistas (Tabela 3). Os entrevistados do setor privado de saúde têm maior percentual de pessoas etilistas, tanto na frequência quanto na variedade de bebidas ingeridas. Na literatura (Castro 2009, Lopes 2016) encontramos que $47,5 \%$ dos entrevistados consumiam bebidas alcoólicas fermentadas e destiladas; $55,25 \%$ utilizavam a bebida de uma a três vezes na semana; $3,4 \%$ acima de quatro vezes na semana; $21,9 \%$ utilizavam a bebida mensalmente e $21,15 \%$ utilizavam raramente algum tipo de bebida. Quanto à frequência do consumo de bebidas alcoólicas: $1 \%$ fazia uso diário de bebida alcoólica; $36,3 \%$ utilizavam 1 a 2 dias por semana; $4,4 \%$ bebiam 3 a 4 dias por semana; $1,5 \%$ bebiam 5 a 6 dias por

Tabela 3 - Distribuição percentual sobre frequência do fumo e média de cigarros utilizados pelos usuários quando fumam. Elaboração: Questionário aplicado pelos autores da pesquisa.

\begin{tabular}{|c|c|c|}
\hline \multicolumn{2}{|c|}{ Setor Privado } & Setor Público \\
\hline & Frequência do fumo & Frequência do fumo \\
\hline Diariamente & $1(2 \%)$ & $3(6 \%)$ \\
\hline Duas a três vezes por semana & $1(2 \%)$ & $3(6 \%)$ \\
\hline Quatro vezes ou mais & $5(10 \%)$ & $0(0 \%)$ \\
\hline Uma vez por mês & $3(6 \%)$ & $0(0 \%)$ \\
\hline Não fumo & $40(80 \%)$ & $44(88 \%)$ \\
\hline & Média de cigarros & $3(6 \%)$ \\
\hline 1 a 2 & $2(4 \%)$ & $3(6 \%)$ \\
\hline 3 a 5 & $3(6 \%)$ & $0(0 \%)$ \\
\hline 6 a 9 & $1(2 \%)$ & $0(0 \%)$ \\
\hline 10 a 20 & $1(2 \%)$ & $2(4 \%)$ \\
\hline Mais de 20 & $2(4 \%)$ & $42(84 \%)$ \\
\hline Zero & $41(82 \%)$ & cigarros \\
\hline
\end{tabular}


semana (diariamente); 5,9\% faziam uso da bebida de 15 em 15 dias; $8,9 \%$ bebiam uma vez por mês e $41,8 \%$ não utilizavam nenhum tipo de bebida alcoólica (Harding \& Sherr 2014, Inca 2014). Ao consumo excessivo de álcool são atribuídas cerca de 50 a 70\% de todas as mortes por câncer de língua, cavidade oral, faringe e esôfago (Lopes 2016).

Prado et al. (2014) obtiveram diferença estatisticamente significativa quando relacionaram os termos "ingerir bebida alcóolica" e "tipos diferentes de bebida" $\left(x^{2}=96,62 ; p<0,001\right)$. Os entrevistados sabem as consequências do uso de bebidas alcoólicas, favorecendo a predisposição a vários tipos de doenças, apesar disso, não suspendem o seu consumo, tornando este hábito um fator de risco significante para o desenvolvimento do CCEO. A maioria afirmou beber "socialmente", em média, dois tipos diferentes de bebidas e ainda associadas ao cigarro. Devido a tal fator, também obtivemos valores significativos em nossa amostra $\left(x^{2}=28,59 ; p<0,027\right)$ quando comparamos o "uso da bebida alcóolica" e "frequência do fumo". A estreita correlação entre casos de câncer oral e hábitos deletérios, como o tabagismo e o alcoolismo, usados isoladamente, são ainda mais acentuados se estiverem associados (Inca 2018).

$\mathrm{Na}$ atualidade, as doenças crônicas não transmissíveis são as principais causas de morte no mundo. Consideradas doenças multifatoriais, elas possuem em comum os fatores de riscos modificáveis, como inatividade física, colesterol elevado, excesso de peso, tabagismo, consumo excessivo de bebidas alcoólicas e alimentação não saudável (Nogueira 2010, Inca 2014), assim como fatores biológicos.

A presença de traumas na mucosa oral, o estresse psicológico, poucas horas de sono, a presença da bactéria Helicobacter pylori que provoca a gastrite, deficiências vitamínicas, alterações hormonais, o cigarro ou aftas (em cerca de $20 \%$ da população), pode favorecer o surgimento de alterações teciduais, podendo evoluir para um CCEO (Brito et al. 2013, Piemonte, Lazos \& Brunotto 2010).

Em nosso estudo, nos usuários do setor privado, 6\% afirmaram a presença de aftas com frequência, abaixo do encontrado por Brito et al. (2013) e Piemonte, Lazos e Brunotto (2010), 16\% possuíam dentes quebrados ou próteses machucando e $36 \%$ mordiam as bochechas ou a língua com certa frequência. Já nos usuários dos usuários do setor público, $34 \%$ afirmaram sofrer com a presença de aftas, percentual superior ao encontrado por Brito et al. (2013) e Piemonte, Lazos e Brunotto (2010), 48\% possuíam dentes quebrados ou próteses machucando e $30 \%$ mordiam as bochechas ou a língua com certa frequência. 
Tabela 4 - Distribuição percentual dos grupos de indivíduos atendidos no sistema de saúde particular e público sobre a condição de sua mucosa oral. Elaboração: Questionário aplicado pelos autores da pesquisa.

\begin{tabular}{|l|c|c|c|c|c|c|}
\hline \multicolumn{1}{|c|}{ Setor privado } & \multicolumn{3}{c|}{ Setor público } \\
\hline & Aftas & $\begin{array}{c}\text { Dentes } \\
\text { quebrados/ } \\
\text { Próteses } \\
\text { machucando }\end{array}$ & $\begin{array}{c}\text { Morde } \\
\text { bochechas/ } \\
\text { Língua com } \\
\text { frequência }\end{array}$ & Aftas & $\begin{array}{c}\text { Dentes } \\
\text { quebrados/ } \\
\text { Próteses } \\
\text { machucando }\end{array}$ & $\begin{array}{c}\text { Morde bochechas } \\
\text { ou a língua com } \\
\text { frequência }\end{array}$ \\
\hline SIM & $3(6 \%)$ & $8(16 \%)$ & $18(36 \%)$ & $17(34 \%)$ & $24(48 \%)$ & $15(30 \%)$ \\
\hline NÃO & $45(90 \%)$ & $41(82 \%)$ & $32(64 \%)$ & $33(66 \%)$ & $26(52 \%)$ & $34(68 \%)$ \\
\hline NÃO SEI & $2(4 \%)$ & $1(2 \%)$ & $0(0 \%)$ & $0(0 \%)$ & $0(0 \%)$ & $1(2 \%)$ \\
\hline
\end{tabular}

\section{ANÁLISE DE ANCESTRALIDADE}

A análise da ancestralidade genômica permite estimar o processo de contribuição dos diferentes macrogrupos humanos que formaram a população brasileira, estabelecendo a base biológica da contribuição das populações parentais (asiática indígena ou ameríndia; africana e europeia). Para a efetiva comparação entre os resultados observados no presente estudo, foi praticado um Painel de Marcadores Informativos de Ancestralidade (MIA), utilizado em casos forenses e estudos de associação com doenças dentro da população brasileira. Analisamos 100 amostras de Belém, das quais obtivemos resultados somente para 93 indivíduos (7 amostras foram retiradas da pesquisa por não possuírem material suficiente para confirmação dos resultados), todos não relacionados do ponto de vista biológico, representando, portanto, grupos familiares distintos. Na análise da distribuição geral da ancestralidade genômica da amostra da cidade de Belém, observou-se uma média de 61,4\% de contribuição europeia, 26,9\% de contribuição nativo americana e 11,7\% de contribuição africana.

Paralelamente, também foi realizada a análise de ancestralidade genômica, considerando os dois setores separadamente, privado e público. $\mathrm{O}$ resultado desta análise geral também não apresentou diferenças entre suas médias. Esses resultados sugerem que os dois setores, privado e o público, apresentam uma distribuição de ancestralidade semelhante, portanto, os resultados podem ser testados e comparados estatisticamente, uma vez que não apresentaram viés de subestruturarão populacional. Os resultados da distribuição de ancestralidade genômica encontrados em nosso trabalho são similares aos descritos por Santos et al. (2010). Os achados encontrados por Manta et al. (2013) também corroboram nossos resultados. 
Tabela 5 - Distribuição categórica da ascendência ameríndia, europeia e africana nos usuários do setor público de saúde (SPUS) e usuários do setor privado de saúde (SPRS).laboração: dos autores 2021.

\begin{tabular}{|c|c|c|}
\hline Ancestralidade Genômica & SPRS & SPUS \\
\hline Ancestralidade Americana & $\mathrm{N}=39$ & $\mathrm{~N}=50$ \\
\hline $5-10 \%$ & - & - \\
\hline $10-20 \%$ & $6(13,96 \%)$ & $9(18,00 \%)$ \\
\hline $20-30 \%$ & $18(41,86 \%)$ & $9(18,00 \%)$ \\
\hline $30-40 \%$ & $6(13,95 \%)$ & $17(34,00 \%)$ \\
\hline $40-50 \%$ & $9(20,93 \%)$ & $10(20,00 \%)$ \\
\hline $50-60 \%$ & - & $5(10,00 \%)$ \\
\hline$>60 \%$ & - & - \\
\hline p-valor & - & 1,000 \\
\hline Ancestralidade Europeia & $\mathrm{N}=43$ & $\mathrm{~N}=50$ \\
\hline $5-10 \%$ & $2(04,65 \%)$ & - \\
\hline $10-20 \%$ & $1(02,33 \%)$ & $2(04,00 \%)$ \\
\hline $20-30 \%$ & $2(04,65 \%)$ & $6(12,00 \%)$ \\
\hline $30-40 \%$ & $2(04,65 \%)$ & $9(18,00 \%)$ \\
\hline $40-50 \%$ & $7(16,28 \%)$ & $17(34,00 \%)$ \\
\hline $50-60 \%$ & $11(25,58 \%)$ & $7(14,00 \%)$ \\
\hline$>60 \%$ & $18(41,86 \%)$ & $9(18,00 \%)$ \\
\hline p-valor & - & 1,000 \\
\hline Ancestralidade Africana & $\mathrm{N}=43$ & $\mathrm{~N}=50$ \\
\hline $5-10 \%$ & $4(09,30 \%)$ & $5(10,00 \%)$ \\
\hline $10-20 \%$ & $17(39,54 \%)$ & $25(50,00 \%)$ \\
\hline $20-30 \%$ & $12(27,90 \%)$ & $12(24,00 \%)$ \\
\hline $30-40 \%$ & $4(09,30 \%)$ & $4(08,00 \%)$ \\
\hline $40-50 \%$ & $1(02,33 \%)$ & $3(06,00 \%)$ \\
\hline $50-60 \%$ & $5(11,63 \%)$ & $1(02,00 \%)$ \\
\hline$>60 \%$ & - & - \\
\hline p-valor & 1,000 & \\
\hline
\end{tabular}




\section{ANÁLISE MIRNALET-7C VS DADOS SOCIOE- CONÔMICOS E ANCESTRALIDADE}

A Teoria do Campo de Cancerização (field effect) sugere a presença de uma área adjacente ao tumor que possui aspecto histopatológico normal, mas que já apresenta alterações moleculares (genéticas e epigenéticas), o que pode alterar a homeostase epitelial predispondo essa região adjacente ao tumor ao desenvolvimento do câncer. Dentre as diversas alterações moleculares estão os microRNAs (miRNAs), reguladores da expressão de genes importantes da via carcinogênica. Avaliar a existência de diferenças significativas na expressão do microRNAs let-7c nos dois grupos (privado e público), levando em conta as diferenças existentes em relação a hábitos deletérios, condições gerais de acesso à assistência médica e odontológica e ancestralidade, era nosso objetivo principal.

Nosso grupo de pesquisa foi o primeiro a realizar o miRnoma (expressão global de microRNAs) em CCEO por meio da plataforma de Sequenciamento de Alto Desempenho (Lopes et al. 2016). Os resultados foram capazes de discriminar o tecido acometido pelo CCEO do tecido normal. Foram descritos no referido estudo sete novos miRNAs, dentre os quais let-7c. A averiguação do miRNA let-7c no CCEO parece coerente, uma vez que participa de processos inflamatórios da cavidade oral com o mesmo perfil de expressão (Lopes et al. 2016, Zhang et al. 2015).

Em nossas análises não obtivemos diferenças estatisticamente significativas entre os dois grupos analisados (setor privado e público). Dessa forma, concluímos que os fatores epigenéticos que regulam o mecanismo de expressão dos genes, como a ação de miRNAs e os outros processos modificadores do ambiente aos quais esses usuários foram expostos, não foram capazes de determinar diferenças significantes na expressão do miRNA let-7c, sendo as médias obtidas para os usuários oriundos do serviço privado de 1,3113555 e do serviço público de $1,02328733(\mathrm{~N}=100 ; \mathrm{p}=0,3897)$ (Figura 5).

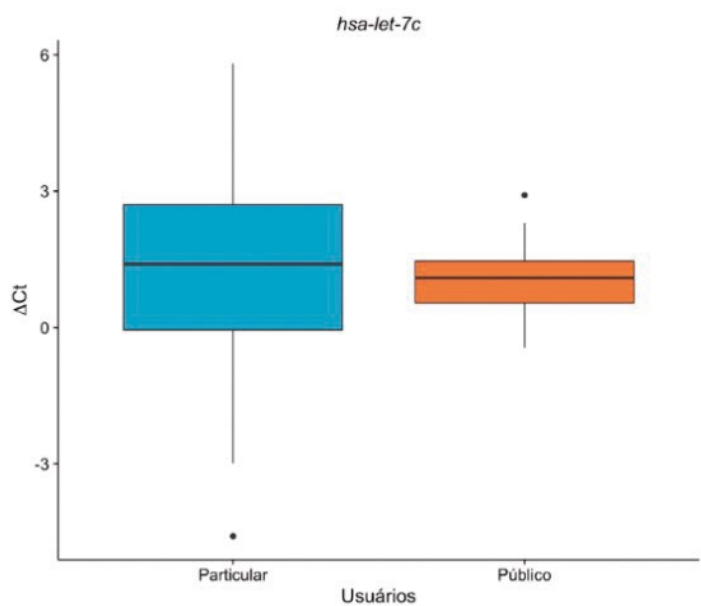

Figura 5 - A figura ilustra um Box Plot de comparação dos níveis de expressão do let-7c nos dois grupos de usuários estudados. Elaboração: dos autores baseados nos protocolos de pesquisa (2021). 
Na literatura avaliada, o câncer resulta do crescimento celular anormal ou da perda da capacidade de apoptose, e os principais elementos que regulam essas duas vias são controlados pelos miRNAs (Bartel 2004, Blot et al. 1988), em que o silenciamento ou a hiperexpressão de miRNAs específicos parecem ser fenômenos essenciais na iniciação e desenvolvimento da doença. Normalmente, os miRNAs que aparecem em níveis elevados (hiperexpressos) em tecidos neoplásicos podem ser considerados oncogenes - "oncomiRs", que atuam promovendo o desenvolvimento tumoral, por meio da inibição de genes supressores tumorais e/ou genes que controlam a diferenciação celular e a apoptose. Em contrapartida, os miRNAs que apresentam expressão diminuída (hipoexpresso) em tecidos tumorais são considerados genes supressores tumorais, como é o caso da família Let-7, onde encontra-se o miRNA let-7c, que usualmente previnem o desenvolvimento tumoral inibindo negativamente a expressão de oncogenes e/ou genes que controlam a diferenciação celular e a apoptose.

Para cada tipo de tecido há um padrão diferenciado da expressão dos miRNAs. Assim, tipos diferentes de tumores mostram padrões de expressão de miRNAs distintos, associados a características clínico-patológicas específicas. Por causa dessa particularidade, esses elementos podem ser usados como biomarcadores, tornandose uma poderosa ferramenta diagnóstica ou de segmento de uma doença (Gonçalves 2016).

Se um microRNA, como o let-7c, sofre uma alteração em sua expressão em determinado tecido, as células podem se desenvolver fora de controle, levando ao desenvolvimento da doença.

A importância da variabilidade da expressão de miRNAs reside no fato de que a família Let7 demonstra agir como supressor de tumor inibindo oncogenes e principais reguladores de vias mitogênicas incluindo RAS, MYC, HMGA2 etc.

Numerosos estudos com câncer mostraram que os níveis de expressão de let-7 são frequentemente baixos e os clusters cromossômicos de let-7 são frequentemente deletados em muitos tipos de cânceres. Let-7é expresso em níveis mais elevados em tumores mais diferenciados, que também têm níveis mais baixos de oncogenes ativados, como RAS e HMGA2.

Na figura 6, mostramos box plots comparando a expressão do microRNA let -7c com a ancestralidade genômica dos dois grupos pesquisados pertencentes à Região Norte do Brasil, mas com hábitos e condições socioeconômicas distintas. 

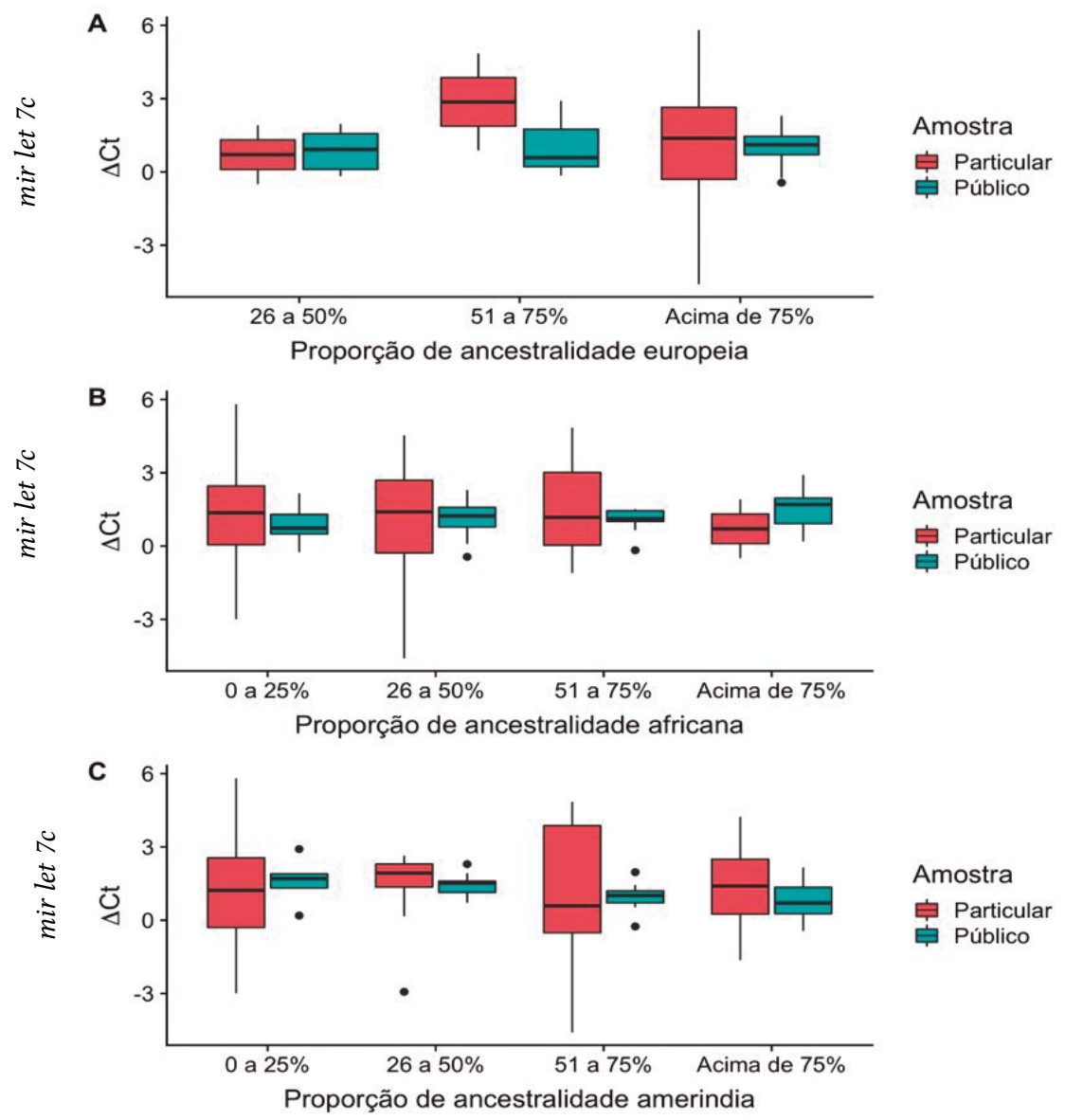

Figura 6 - Box Plot relacionando a expressão do microRna let $7 c$ com a ancestralidade dos dois setores da Pesquisa. Elaboração: dos autores, baseados nos protocolos de pesquisa (2021).

A análise da expressão do microRNA let$7 c$ não apresentou influência da ancestralidade genômica, mesmo considerando as diferenças socioeconômicas observadas nos dois grupos investigados. Portanto, os dados obtidos sugerem que a expressão semelhante desse biomarcador entre os dois serviços de saúde oferecidos para a população de Belém (privado e público) pode ser utilizador como balizador do mecanismo de adoecimento nesta população. Esses resultados também sugerem que o processo de miscigenação dos povos formadores da população de Belém serve como ferramenta para as análises de mudança de perfil de expressão e, consequentemente, de risco para várias doenças, inclusive o câncer oral. 


\section{CONCLUSÕES}

A amostra investigada foi bastante heterogênea em relação às diversas variáveis, apesar disso, não apresentou diferenças estatísticas significativas em relação à expressão do microRNA let-7c. As implicações em se trabalhar com pacientes saudáveis nos dois grupos de estudo tinha como objetivo avaliar se as influências ambientais e de hábitos pessoais de cada grupo e indivíduo seriam suficientes para modificar o padrão de expressão diferencial do microRNA Let-7c. Entretanto, não obtivemos um valor de " $p$ " estatisticamente significativo nos diferentes grupos. Observamos uma maior elevação da expressão do microRNA let-7c no grupo proveniente do setor privado, de usuários que relataram diagnósticos anteriores com outros tipos de câncer não oral. Esse fato pode ter influenciado na elevação da expressão desse microRNA, porém, como o número amostral foi relativamente pequeno e não obtivemos um valor de "p" estatisticamente significativo, não podemos afirmar que há expressão distinta entre esses dois grupos. Na presente amostra, o biomarcador let-7c não apresentou influência da ancestralidade genômica em sua expressão, portanto, os dados obtidos sugerem que a expressão desse biomarcador foi semelhante entre os dois serviços de saúde oferecidos para a população de Belém (privado e público).

Dessa forma, o let-7c pode ser utilizado como uma ferramenta a mais em estudos comparativos relacionados ao câncer ou as doenças infectocontagiosas. Há, portanto, um vasto campo para que novas investigações possam validar os resultados observados no presente estudo, sempre na intenção de encontrar meios que possam auxiliar os profissionais de saúde a intervir precocemente às enfermidades, por meio da identificação prematura de biomarcadores alterados, o que pode auxiliar na busca de tratamentos menos invasivos e com melhores prognósticos. 


\section{REFERÊNCIAS}

Allgayer, Heike. 2010. Pdcd4, a colon cancer prognostic that is regulated by a microRNA. Critical Reviews in Oncology/Hematology. 73(3):185-91. 10.1016/j.critrevonc.2009.09.001

Ambros, Victor. 2004. The functions of animal microRNAs. Nature. 431(7006): 350-5. 10.1038/ nature 02871

Andreghetto, Flavia Maziero et al. 2011. Avaliação da expressão de microRNAs em linhagens celulares de carcinoma epidermóide de cabeça e pescoço e em cultura primária de queratinócitos orais. EINSEinstein. 94: 442-448. http://dx.doi.org/10.1590/S1679-45082011AO2149

Argyris, Jason et al. 2008. Genetic and hormonal regulation of seed thermoinhibition. Plant Physiology Preview. 148(2): 926-47. 10.1007/978-3-319-14451-1_1

Avissar, Michelle et al. 2009. MicroRNA expression ratio is predictive of head and neck squamous cell carcinoma. Clinical Cancer Residence. 15(8): 2850-5. 10.1158/1078-0432.CCR-08-3131

Avissar, Michelle; McClean, Michael, Kelsey, Karl e Marsit, Carmen. 2009. MicroRNA expression in head and neck cancer associates with alcohol consumption and survival. Carcinogenesis. 10.1093/ carcin/bgp277

Avissar-Whiting Michelle et al. 2010. Bisphenol A exposure leads to specific microRNA alterations in placental cells. Reprodutive Toxicology. 29(4):401-6. 10.1016/j.reprotox.2010.04.004

Banerjee, Sami. 2013b. MicroRNA let-7c Regulates Macrophage Polarization. The fournal of Immunology. 190: 6542-6549. 10.4049/jimmunol.1202496

Bartel, David P. 2004. MicroRNAs: genomics, biogenesis, mechanism, and function. Cell. 116(2): 28197. $10.1016 / \mathrm{s} 0092-8674(04) 00045-5$

Bartel, David P. et al. 2008. Early origins and evolution of microRNAs and Piwi-interacting RNAs in animals. Nature. 455:1193-1197. 10.1038/nature07415

Blot, Willian J. et al. 1988. Smoking and drinking in relation to oral and pharyngeal câncer. Câncer Research. 48:3282-7. 10.1007/s10552-007-9026-4

Bourguignon, Lily Y. W. 2012. Hyaluronan-CD44 interaction promotes microRNA signaling and RhoGTPase activation leading to tumor progression. Small GTPases. 3(1): 53-9. 10.4161/sgtp.19110 
Brasil. 2004. Informações de saúde: estatísticas vitais/mortalidade geral. http://www.datasus.gov.br/

Brito, João A. R. et al. 2013. Relationship between microRNA expression levels and histopathological features of dysplasia in oral leukoplakia. Fournal of Oral Pathology and Medicine. 43 (3): 211-216. 10.1111/jop. 12112

Calin, George A. et al. 2007. Ultraconserved regions encoding ncRNAs are altered in human leukemias and carcinomas. Cancer Cell. 12(3): 215-29. 10.1016/j.ccr.2007.07.027

Castro, Regina. 2009. Câncer na mídia: uma questão de saúde pública. Revista Brasileira de Cancerologia. 55(1): 41-48. https://doi.org/10.32635/2176-9745.RBC.2009v55n1.1675

Cavalcante, Giovanna C. et al. 2019. A Cell's Fate: An Overview of the Molecular Biology and Genetics of Apoptosis. International fournal of Molecular Science. 20(17): 4133. 10.3390/ijms20174133

Cardena, Mari M.S.G. et al. 2014. Amerindian genetic ancestry is associated with higher survival rates compared to African and European ancestry in Brazilian patients with heart failure. International fournal of Cardiology. 176: 527-528. https://doi.org/10.1016/j.ijcard.2014.07.039

Cervigne, Nilva Ket al. 2009. Identification of a microRNA signature associated with progression of leukoplakia to oral carcinoma. Human Molecular Genetical. 18(24):4818-29. 10.1093/hmg/ddp446

Colares, Vinícius Sardão et al. 2014. MYH9 and APOL1 Gene Polymorphisms and the Risk of CKD in Patients with Lupus Nephritis from an Admixture Population. Plos One. 9: e87716. 10.1371/journal. pone.0087716

Dantas, Élida Lívia Rafael et al. 2009. Genética do Câncer Hereditário. Revista Brasileira de Cancerologia. 2009. 55(3): 263-9. https://rbc.inca.gov.br/revista/index.php/revista/article/view/1619

El-Hani, Charbel Niño; Queiroz, João e Emmeche, Claus. 2006. A semiotic analysis of the genetic information system. Semiotica. 160: 1-68. 10.1515/SEM.2006.039

Farazi, Thalia A. et al. 2011. MicroRNA sequence and expression analysis in breast tumors by deep sequencing. Cancer Residencial. 77 (8): 2052-2063. 10.1158/0008-5472.CAN-11-0608

Fassina, Ambrogio; Cappellesso, Rocco e Fassan, Matteo. 2011. Classification of non-small cell lung carcinoma in transthoracic needle specimens using microRNA expression profiling. Chest. 140(5): 1305-1311. 10.1378/chest.11-0708 
Ferlay, Jacques et al. 2010. Estimates of worldwide burden of cancer in 2008: GLOBOCAN 2008. International fournal of Cancer. 127(12): 2893-917. 10.1002/ijc.25516

Ferreira, Lucas Lima; Pereira, Carolina Benfantti, Dias, Marília Armiato e Alves, Sueli Aparecida. 2013. Análise da dependência do tabaco e da qualidade de vida de indivíduos fumantes. Revista Inspirar. 5 (1-22):1-5.

Feng Zhi et al. 2013. A microRNA expression signature predicts meningioma recurrence. International fournal of Cancer. 132 (1): 128-136. 10.1002/ijc.27658

Friedman, Robin C. et al. 2009. Most mammalian mRNAs are conserved targets of microRNAs. Genome Research. 19: 92-105. 10.1101/gr.082701.108

Glaser, Brian T. et al. 2009. Studying the salt dependence of the binding of sigma70 and sigma32 to core RNA polymerase using luminescence resonance energy transfer. Plos One. 4(8): e6490. 10.1371/ journal.pone.0006490

Gonçalves, Jussara Maria. 2016. Análise da expressão imuno-histoquímica das proteínas P53, USP1 e WDR48 com os dados clínico-histopatológicos em carcinomas epidermóide intrabucais. Dissertação de mestrado, Universidade Federal de Santa Catarina, Centro de Ciências da Saúde, Programa de Pós-Graduação em Odontologia, Florianópolis.

Guerra, Maximiliano Ribeiro; Moura Gallo, Cláudia Vitória e Mendonça, Guinar Azevedo e Silva. 2005. Risco de câncer no Brasil: tendências e estudos epidemiológicos mais recentes. Revista Brasileira de Cancerologia. 51(3): 227-234.

Hanahan, Douglas e Weinberg, Robert A. The hallmarks of cancer. 2000. Cell. 100(1): 57-70. 10.1016/ s0092-8674(00)81683-9

Harding, Richard e Sherr, Lorraine. 2014. Comment on "Pain in people living with HIV/AIDS: a systematic review (Parker et al. 2014)". Journal of the International of AIDS Society. 17(1): 19096. 10.7448/IAS.17.1.19096

Harris, Simon R. et al. 2012. Evolution of MRSA During Hospital Transmission and Intercontinental Spread. Science. 327 (5964): 469-474. 10.1126/science.1182395 
Huang, Da Wei; Sherman, Brad T. e Lempicki, Richard. 2009b. Systematic and integrative analysis of large gene lists using DAVID bioinformatics resources. Nature Protocols. 4: 44-57. 10.1038/ nprot.2008.211

Huang, Yin-Hen et al. 2009. Epigenetic Repression of microRNA-129-2 Leads to Overexpression of SOX4 Oncogene in Endometrial Cancer. Cancer Research. 69 (23): 9038-46. 10.1158/0008-5472.CAN09-1499

Hui, Angela B. et al. 2010. Comprehensive MicroRNA profiling for head and neck squamous cell carcinomas. Clinical Cancer Research. 16:1129-1139. 10.1158/1078-0432.CCR-09-2166

Hukkanen, Janne; Pleyton, Jacob III e Benowitz, Neal L. 2005. Metabolism and disposition kinetics of nicotine. Pharmacological Reviews. 57(1): 79-115. https://doi.org/10.1124/pr.57.1.3

Hung, Shih-Chiang et al. 2014. Determining delayed admission to the intensive care unit for mechanically ventilated patients in the emergency department. Critical Care. 18(4): 485. 10.1186/ s13054-014-0485-1

Inca. 2014. Estimativa 2014: incidência de câncer no Brasil. Rio de Janeiro: Inca.

Inca. 2018. Estimativa 2018: incidência de câncer no Brasil. Rio de Janeiro: INCA.

Ivanovska, Irena e Cleary, M. A. 2008. Combinatorial microRNAs: working together to make a difference. Cell Cycle. 7(20): 3137-42. https://doi.org/10.4161/cc.7.20.6923

Ivey, Kathryn N. e Srivastava, Deepak. 2010. MicroRNAs as regulators of differentiation and cell fate decisions. Cell Stem Cell. 7(1): 36-41. 10.1016/j.stem.2010.06.012

Jemal, Ahmedin et al. 2009. Cancer Statistics. CA: A Cancer fournal for Clinicians. 59(4):225

http://dx.doi.org/10.3322/caac.20006

Kawakita, Akiko. 2014. MicroRNA-21 Promotes Oral Cancer Invasion via the Wnt/ $\beta$-Catenin Pathway by Targeting DKK2. Pathology \& Oncology Research. 20 (2): 253-261. 10.1007/s12253-013-9689-y

Krek, Azra et al. 2005. Combinatorial microRNA target predictions. Nature Genetics. 37(5): 495-500. https://doi.org/10.1038/ng1536 
Leite, Kátia R. M. et al. 2010. MicroRNA-100 Expression is Independently Related to Biochemical Recurrence of Prostate Cancer. Fornal of Urology. 185(3):1118-22. 10.1016/j.juro.2010.10.035

Lewis, Benjamin; Burge, Christopher B. e Bartel, David. 2005. Conserved Seed Pairing, Often Flanked by Adenosines, indicates that Thousands of Human Genes are MicroRNA Targets. Cell. 120 (1): 1520. 10.1016/j.cell.2004.12.035

Lima, Marco Antônio Pereira de; Silva, Lima, Claúdio Gleiston da Silva e Rabenhorst, Sílvia Helena. 2014. Association between human papillomavirus (HPV) and the oral squamous cell carcinoma: a systematic review. Jornal Brasileiro de Patologia e Medicina Laboratorial. 50(1):75-84. http://dx.doi. org/10.1590/S167624442014000100011

Linhares, Amanda Guedes. 2014. Efeito de pesticidas organofosforados e carbamatos sobre a acetilcolinesterase eritrocitária humana e seu potencial uso como biomarcardor da exposição ocupacional. Dissertação de mestrado, Pós-graduação em Ciências Biológicas Universidade Federal de Pernambuco, Recife.

Lo, Hisiao-Chi. C. et al. 2012. Cdc7-Dbf4 is a gene-specific regulator of meiotic transcription in yeast. Molecular. Cell Biology. 32(2): 541-57. 10.1128/MCB.06032-11

Lopes, Camile de B. 2016. Perfil de Expressão de MicroRNAs no câncer oral. 118 f. Tese de doutorado, Programa de Pós-Graduação em Genética e Biologia Molecular, Universidade Federal do Pará, Belém.

Manta, Fernanda Saloum de Neves et al. 2013. Revisiting the Genetic Ancestry of Brazilians Using Autosomal AIM-Indels. Plos One. 8(9): e75145. https://doi.org/10.1371/journal.pone.0075145

Min, Anjie et al. 2015. MicroRNAs as Important Players and Biomarkers in Oral Carcinogenesis. BioMed Research International. 2015: 1-10. 10.1155/2015/186904

Moro, Juliana da Silva et al. 2018. Câncer de boca e orofaringe: epidemiologia e análise da sobrevida. Einstein. 16(2): eAO4248. 10.1590/S1679-45082018AO4248

Näsman, Anders et al. 2009 Incidence of human papillomavirus (HPV) positive tonsillar carcinoma in Stockholm, Sweden: an epidemic of viral-induced carcinoma? International fournal of Cancer. 125: 362-366. https://doi.org/10.1002/ijc.24339

Nogueira, Roberto Passos. Organizador. 2010. Determinação Social da Saúde e Reforma Sanitária. Rio de Janeiro: Cebes. 
O’Donnell, Rebekah K. et al. 2005. Gene expression signature predicts lymphatic metastasis in squamous cell carcinoma of the oral cavity. Oncogene. 24: 1244-1251.

Oliveira, Marco Antônio de. 2016. Estudo da participação de microRNAs na regulação da resposta imune inata de macrófagos murinos à infecção por Paracoccidioides brasiliensis. Dissertação de mestrado, Instituto de Ciências Biológicas, Departamento de Biologia Celular, Universidade de Brasília, Brasília.

Ota, Vanessa Kiyomi et al. 2013. Candidate genes for schizophrenia in a mixed Brazilian population using pooled DNA. Psychiatry Research. 208(2): 201-2. 10.1016/j.psychres.2012.12.009

Prado, Bernadete Bisi Franklin. 2014. Influência dos hábitos de vida no desenvolvimento do câncer. Ciência e Cultura. 66 (1): 21-24. http://dx.doi.org/10.21800/S0009-67252014000100011

Pereira, Rui et al. 2019. Straightforward inference of ancestry and admixture proportions through ancestry-informative insertion deletion multiplexing. Plos One. 7(1): e29684. https://doi.org/10.1371/ journal.pone.0029684

Piemonte, Eduardo David; Lazos, Jerônimo Pablo e Brunotto, Mabel. 2010. Relationship between chronic trauma of the oral mucosa, oral potentially malignant disorders and oral cancer. Oral Patholology of Medicine. 39(7): 513-17. 10.1111/j.1600-0714.2010.00901.x

Pritchard, Jonathan K. et al. 2000. Association mapping in structured populations. American fournal of Human Genetical. 67(1): 170-81. 10.1086/302959

Reis, S. T. et al. 2010. MicroRNA-100 Expression is Independently Related to Biochemical Recurrence of Prostate Cancer. Fornal of Urology. 185(3):1118-22. 10.1016/j.juro.2010.10.035

Ren, Yu et al. 2010. MicroRNA-21 inhibitor sensitizes human glioblastoma cells U251 (PTEN-mutant) and LN229 (PTEN-wild type) to taxol. BMC Cancer. 10 (27). 10.1186/1471-2407-10-27.80

Ross, Sharon A. e Davis, Cindy. 2011. MicroRNA, nutrition, and câncer prevention American Society for Nutrition. Advances in Nutrition. 2(6): 472-485. https://doi.org/10.3945/an.111.001206

Santhi, W. S. et al. 2013. Oncogenic microRNAs as biomarkers of oral tumorigenesis and minimal residual disease. Oral Oncology. 49(6). 10.1016/j.oraloncology.2013.01.001 
Santos, Ney P. C. et al. 2010. Assessing individual interethnic admixture and population substructure using a 48-insertion-deletion (INSEL) ancestry-informative marker (AIM) panel. Human Mutation. 31:184-90. 10.1002/humu.21159

Shiiba, Masashi et al. 2013. MicroRNA-125b regulates proliferation and radioresistance of oral squamous cell carcinoma. British fournal of Cancer. 108(9): 1817-21. 10.1038/bjc.2013.175

Silveira, Augusta et al. 2012. Head and Neck Cancer: Health Related Quality of Life Assessment considering clinical and epidemiological perspectives. Revista Brasileira de Epidemiologia. 15(1): 3848. 10.1590/s1415-790x2012000100004

Stephens, Matthew e Donnelly, Peter. 2003. A comparison of bayesian methods for haplotype reconstruction from population genotype data. American fournal of Human Genetic. 73(5):1162-9. $10.1086 / 379378$

Tomasetti, Cristian; Lu Li e Vogelstein, Bert. 2017. Stem cell divisions, somatic mutations, cancer etiology, and cancer prevention. Science. 355(6331):1330-1334. 10.1126/science.aaf9011

Vigitel. Brazil 2018: surveillance of risk and protective factors for chronic diseases by telephone survey: estimates of frequency and sociodemographic distribution of risk and protective factors for chronic diseases in the capitals of the 26 Brazilian states and the Federal District in 2018. http://bvsms.saude. gov.br/bvs/publicacoes/vigitel_brasil_2018_vigilancia_fatores_risco.pdf

Yanaihara, Nozomu et al. 2006. Unique microRNA molecular profiles in lung cancer diagnosis and prognosis. Cancer Cell. 9(3):189-98. 10.1016/j.ccr.2006.01.025

Yang, Chengzhi et al. 2014. Regulation of cell survival by the HIP-55 signaling network. Molecular Omics. 10 (6):1393-9. 10.1039/c3mb70552h

Zhang, Chen-Lu et al. 2015. Prognostic role of the let-7 family in various carcinomas: A meta-analysis update. Journal of the Balkan Union of Oncology. 20(2): 631-44. PMID: 26011360 